\title{
The Ophthalmology Specialty Group and the National Institute for Health Research: the first 6 years
}

\section{Eye (2013) 27, 457-460; doi:10.1038/ eye.2013.22}

In 2006, the Department of Health set up the National Institute for Health Research (NIHR) to create a world-class health research system within the National Health Service (NHS). ${ }^{1}$ Current (2012/13) government funding for the NIHR stands at $£ 285$ million. Central to this is the NIHR Clinical Research Network, which consists of a national coordinating centre, six topic-specific research networks (cancer, stroke, dementia, diabetes, mental health, and medicines for children), a primary-care research network and a comprehensive clinical research network (CCRN) to cover all other areas of clinical need, including Ophthalmology (http://www.crncc.nihr.ac.uk/about_us/ccrn/ specialty).

The CRN is responsible for a database known as the NIHR CRN portfolio (http:/ / www.crncc.nihr.ac.uk/about_us/processes / portfolio), a collection of high-quality clinical studies, many of which are randomised controlled trials. Only studies included, termed 'adopted', in this database have access to infrastructure and NHS service support costs. Studies are automatically eligible for inclusion on the national portfolio if they are funded by NIHR, other areas of government, or NIHR noncommercial partners. These non-commercial partners are organisations that (i) award funds as a result of open national competition with high-quality peer review, (ii) fund research that is of clear benefit to the NHS, and (iii) have a strategic direction for the research they fund that takes into account Department of Health and NHS priorities and needs. Other studies require formal consideration to be adopted onto the national portfolio and include (i) studies that are industry supported and sponsored, (ii) studies that are industry supported but not
R Bourne ${ }^{1}$ and $R$ Gale ${ }^{2}$ on behalf of the Ophthalmology Specialty Group

sponsored (investigator-led collaborations), and (iii) studies funded by overseas agencies (eg National Institutes of Health or European Union Framework Programmes).

The CRN has set several high-level objectives (http:/ / www.crncc.nihr.ac.uk/about_us/ performance_objectives), which act as a management mechanism to drive forward performance by setting defined and agreed criteria for gauging improvement over time. These objectives are focused on delivery outcomes with specific objectives for 2010-2015 that include:

(i) doubling the number of participants recruited into NIHR CRN portfolio studies;

(ii) increasing the proportion of studies in the NIHR CRN portfolio delivering to target and time;

(iii) increasing the percentage of commercial contract studies delivered through the NIHR CRN;

(iv) increasing the percentage of NHS trusts participating in NIHR CRN portfolio studies.

This is particularly important for researchers working on commercial life-sciences studies, given that the United Kingdom must compete with other countries to host studies that could benefit NHS patients. The practical support involves reducing the bureaucracy involved with setting up studies and the funding of the research and facilities such that they do not drain core NHS resources. By supporting research posts and costs, a much wider range of NHS trusts are now involved, when previously research was the preserve of large teaching hospitals. Consequently, many more patients across England are aware of and have increased access to clinical studies. This development may
${ }^{1}$ Vision \& Eye Research Unit, Postgraduate Medical Institute, Anglia Ruskin University, Cambridge, UK

${ }^{2}$ York Teaching Hospital NHS Foundation Trust, York, UK

Correspondence:

R Bourne, Vision \& Eye Research Unit, Postgraduate Medical Institute, Anglia Ruskin University, Cambridge CB1 1PT, UK

Tel: + 44 (0) 7931 541295;

Fax: + 44 (0) 1480442839

E-mail: rb@rupertbourne. co.uk 
1 Birmingham and the Black Country

Professor Jonathan Gibson and Miss Saaeha Rauz

2 Central and East London

Professor Peng Khaw

3 Cheshire and Merseyside

Professor Simon Harding

4 County Durham and Tees Valley

$5 \quad$ Cumbria and Lancashire

6 Essex and Hertfordshire

Mr Niral Karia

7 Greater Manchester

Dr Tariq Aslam

8 Hampshire and Isle of Wight

Professor Andrew Lotery

$9 \quad$ Kent and Medway

Mr Frank Ahfat and Mr Nilesh Patel

10 Leicestershire, Northamptonshire and Rutland Professor Irene Gottlob

11 London (North West)

12 London (South)

Professor Christopher Hammond

13 Norfolk and Suffolk

Dr Clive Edelsten

14 North and East Yorkshire and Northern Lincolnshire

Mr Richard Gale

15 Northumberland Tyne and Wear

Mr David Steel

16

Peninsula

17

South Yorkshire

Mr Christopher Brand

18

Surrey and Sussex

Mrs Geeta Menon

19

Thames Valley

Ms Susan Downes

20

21

West Anglia

Professor Rupert Bourne

22

Western

Professor Andrew Dick

23

West Midlands (North)

Professor Yit Chiun Yang

24

West Midlands (South)

Mr Sergio Pagliarini

25

West Yorkshire

Mr Farique Ghanchi

26

Northern Ireland

Professor Usha Chakravarthy (Chair)

27

Scotland

Professor Augusto Azuara-Blanco

28

Wales

Dr Tom Margrain
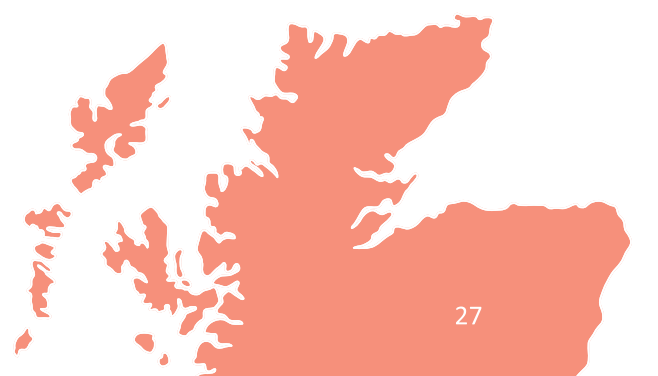

London

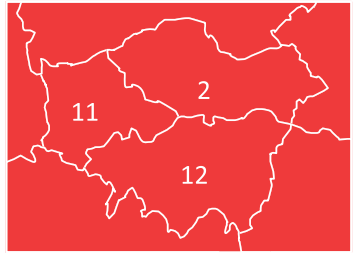

Figure 1 CLRNs where Ophthalmology has been nominated as a local priority with the corresponding local leads (updated September 2012). 
result in better health outcomes, as suggested by some studies where patients cared for in research-active institutions have been reported as having better outcomes than those cared for in a non-research environment. ${ }^{2}$

To assist with the CRN's objectives, a series of national specialty groups were set up, one of which is the Ophthalmology Specialty Group (OSG) (http:/ / www.crncc.nihr.ac.uk/about_us/ccrn/specialty/ ophthalmology/ophthalmology.htm). The OSG has wide geographical coverage, with 22 of the 25 comprehensive local research networks (CLRNs) having nominated a lead in this specialty group area, and nominated leads for Wales, Scotland, and Northern Ireland (Figure 1).

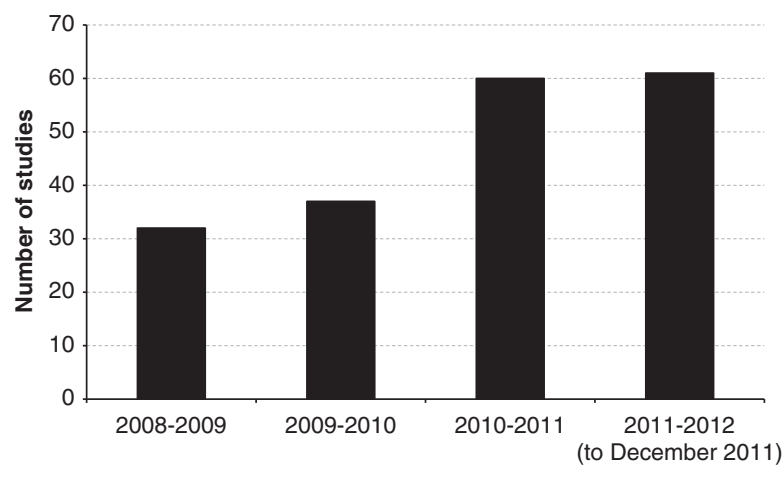

Year that these studies were open to recuitment

Figure 2 Numbers of studies on the Ophthalmology portfolio that were open to recruitment since 2008, each year period given as 30 June to 30 June, except for 2010-2011 (for which data are available only until 31 December 2011).
Clinicians interested in NHS research in Ophthalmology or allied fields are encouraged to seek out their local OSG leads, as there is considerable variability in funding streams and funding allocations in each of the regions. The OSG has several roles, which include the provision of early advice on whether a potential study, either commercial or non-commercial, will be supported by the clinical community and is achievable within the NHS.

Additionally, the group offers detailed advice on feasibility, such as potential numbers of investigators and patients in each site. Members of the OSG do this by providing input to adoption committees, both for commercial trials and for non-commercial trials, which are not automatically eligible for the portfolio.

As of 23 May 2012, there were a total of 1763 open studies (open to recruitment) on the portfolio, of which $93(5.3 \%)$ were led (the primary topic of interest being Ophthalmology) and 12 co-supported (where Ophthalmology specialists have an influence on patient recruitment).

Since the development of the CLRN infrastructure, there has been a progressive increase in the number of studies, as shown in Figure 2. These are represented by region in the United Kingdom in Figure 3. Of the 14 Ophthalmology studies that closed between 30 June 2010 and 30 June 2011, only 6 (43\%) recruited to target in terms of the numbers of patients required and the anticipated time period of the study as set by the chief investigator at the time the study was added to the portfolio (which precedes recruitment). This measure of performance is approximately mid-range when considering all specialties (Figure 4); however, it does highlight the importance of setting realistic targets for recruitment

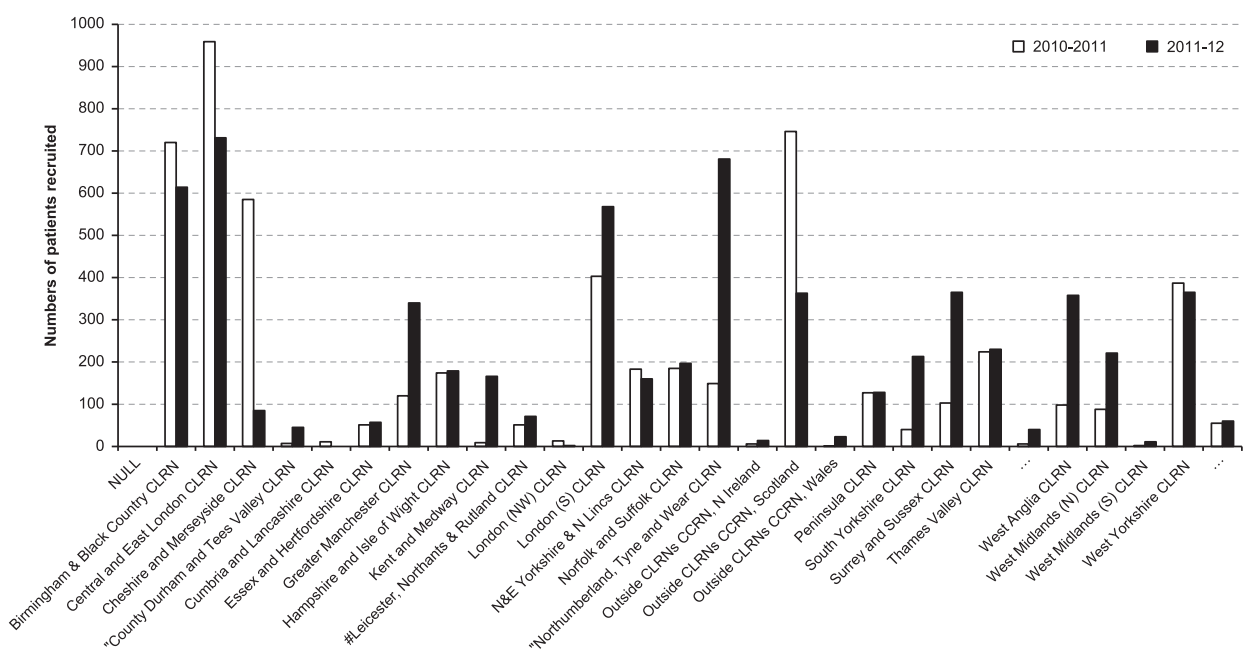

Figure 3 Numbers of patients recruited by comprehensive local research networks and devolved nations for studies categorised to the Ophthalmology Specialty Group, for the past 2 years (each year period given as 1 April to 31 March; figures are taken from the Specialty Group Management reports (based on live date) published on 3rd April 2012). 


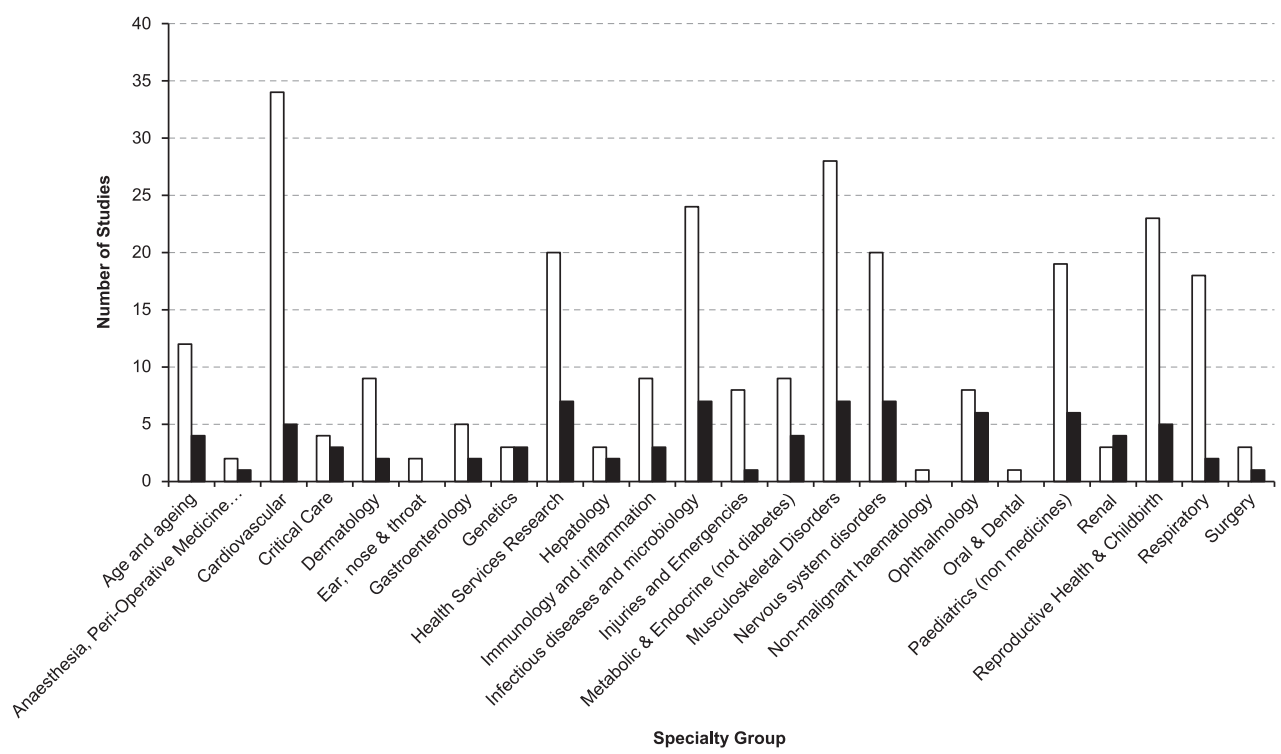

Figure 4 Studies closing between 30 June 2010 and 30 June 2011 by specialty group. For each specialty group the numbers of studies recruiting to target (ie, recruited to total sample size within the timeframe specified by the chief investigator of the study when the study was added to the NIHR portfolio in advance of recruitment) are given as filled bars, while unfilled bars indicate the number of studies that did not achieve the target.

Table 1 Subspecialty-specific breakdown of commercial and non-commercial studies categorised to the Ophthalmology Specialty Group, which are classified as open on the NIHR portfolio (last accessed on 8 June 2012)

\begin{tabular}{lcc}
\hline $\begin{array}{l}\text { Subcategorised Ophthalmology } \\
\text { portfolio studies }\end{array}$ & $\begin{array}{c}\text { Non-commercial } \\
\text { studies }\end{array}$ & $\begin{array}{c}\text { Commercial } \\
\text { studies }\end{array}$ \\
\hline Anterior segment and cataract & 16 & 0 \\
Glaucoma & 13 & 3 \\
Neuro-ophthalmology & 6 & 0 \\
Ocular inflammation & 7 & 5 \\
Refraction and optometry & 2 & 0 \\
Retina (including diabetes) & 28 & 6 \\
Strabismus/paediatrics & 11 & 0 \\
Other & 9 & 0 \\
Total & 92 & 14 \\
\hline
\end{tabular}

when planning studies. Of the open studies, 14 (15\%) were commercial and $79(85 \%)$ non-commercial; the breakdown by disease group is presented in Table 1 .

Considering the types of study open on 23 May 2012, $18 \%$ were clinical trials involving medicinal products as interventions in diseases of the eye and optic nerve, $7 \%$ involved the study of devices in diseases of the eye and optic nerve, $11 \%$ were studies and trials of childhood visual disorders, 3\% were longitudinal observational studies or those documenting natural history, 26\% investigated the risk factors, genetics, and pharmacogenomics of eye diseases, and $10 \%$ were clinical trials involving surgical interventions.
The numbers of NHS patients participating in clinical research in England has greatly increased since the new infrastructure has been implemented, with the NIHR achieving one of its goals of doubling the number of participants recruited into NIHR CRN portfolio studies.

Along with other stakeholders, such as the Royal College of Ophthalmologists, the OSG is working to ensure that new developments in the field of Ophthalmology research are supported by an ongoing stream of clinically relevant research studies, which can be feasibly delivered in the NHS setting.

\section{Conflict of interest}

The authors declare that they have no conflict of interest.

\section{Acknowledgements}

We thank Sarah Cooper and Catherine Bennett (NIHR) for extending their support to this study.

\section{References}

1 Department of Health (2006). Best Research for Best Health: a new national health research strategy. DoH: London. Available online at: http:/ / www.dh.gov.uk/en/Publicationsandstatistics / Publications/PublicationsPolicyandGuidance/DH_4127127.

2 Majumdar SR, Roe MT, Peterson ED, Chen AY, Gibler WB, Armstrong PW. Better outcomes for patients treated at hospitals that participate in clinical trials. Arch Intern Med 2008; 168(6): 657-624 